\title{
Several Reflections on Postgraduate Innovation and Entrepreneurship Education
}

\author{
Yang-Xia OU ${ }^{1, a,{ }^{*}}$, Si WU ${ }^{1, b}$
}

${ }^{1}$ Marxism College, East China Institute of Technology, Jiangxi Fuzhou 344000, China

axouyang@ecit.cn, ${ }^{b}$ zhrliu@qq.com

${ }^{*}$ Corresponding Author

Keywords: Postgraduates, Innovation and entrepreneurship education, Thinking, Policy.

\begin{abstract}
With the dramatic increase in the number of postgraduate, employment of postgraduate is also facing unprecedented pressure. The fundamental way to solve the employment is innovation and entrepreneurship. The current situation and problems of innovation and entrepreneurship education for postgraduates is analyzed, and a few suggestions and thoughts for postgraduate education innovation and entrepreneurship awareness were put forward. This paper aims to train postgraduates with a sense of innovation and entrepreneurship senior personnel. The results will help our government develop innovation and entrepreneurship education and related services, security and incentive policies.
\end{abstract}

\section{Introduction}

"National medium and long-term educational reform and development program (2010-2020)," pointed out: "Improving quality of personnel training, strengthening employment entrepreneurship education and employment guidance services." At present, the enrollment of postgraduate has increased to 397,000 in 2000 to 1.4 million in 2010, nearly 4 -fold during ten years. According to the "National medium and long-term educational reform and development program (2010-2020)", the number of postgraduate in 2020 will be close to 200 million. With the dramatic increase in the number of postgraduate, employment of postgraduate is also facing unprecedented pressure. It is particularly important for postgraduate to timely promote self-employment and self-employed behavior, conduct innovation and entrepreneurship education themselves.

Education is a new advanced educational thought and philosophy. It aims to cultivate a sense of innovation, creativity, critical thinking and creative talents. Entrepreneurship education is a kind of commercial and industrial activities of postgraduates with comprehensive capacity. Entrepreneurship education will help postgraduates to become from purely professional job seekers to job creators with the comprehensive pioneering spirit and entrepreneurial spirit. Entrepreneurship education is an important part of creative spirit and innovative spirit in order to promote extensive development. The concept of these innovative education and entrepreneurship education combines innovation education with entrepreneurship education collectively. It includes innovation and entrepreneurship qualities (such as awareness of innovation and entrepreneurship, spirit of innovation and entrepreneurship, personality of innovation and entrepreneurial, etc.), creative thinking, innovation and entrepreneurial skills and education. Innovation and entrepreneurship education originate from innovative education, entrepreneurship education and professional education through the development of new teaching model, focusing on the quality of postgraduates in practice [1]. Postgraduates can recognize self and life, form a good self-image, enhance innovation spirit and dedication, continually tap the potential of students and reach their innovative entrepreneurial behavior [2]. Through innovation and entrepreneurship education, it is to provide a high level of social and economic development of the human being in order to meet the challenges of the knowledge economy and improve the quality of higher education and multi-orientation. 
Currently, innovation and entrepreneurship education has become widespread concern in the field of education abroad.

\section{The status of postgraduate education innovation and entrepreneurship training}

\section{Lack of innovation and entrepreneurship community leads to poor awareness of postgraduate entrepreneurship}

Postgraduate not only pursue academic frontier, but also use innovative knowledge to achieve the scientific and technological wealth as soon as possible. and promote China's economic development and social progress. Although our country achieves ripe fruits, but the transfer ratio of research achievements is below $10 \%$. There is a large gap between our country and other developed countries.

Currently, social and universities have a simple opinion of postgraduate. The university's "employment rate" is an important criterion for its educational quality. A few postgraduates pay attention to "employed rate." Evaluation of postgraduate is simply to see whether he is able to find a high social status, identity and high salary. The social and universities' conduct on postgraduate entrepreneurship policy support more limited hardly appeal to students. These negative factors can not be formed naturally favorable for innovation and entrepreneurship education atmosphere. In addition, as the quality of employment in recent years, undergraduate and greater employment pressure is not high enough for the majority of postgraduate employment to find a good job. Postgraduate employment crisis generally leads weak sense of survival, strong psychological comfort, relatively weak entrepreneurial awareness. However weak entrepreneurial awareness makes postgraduate entrepreneurship for the accumulation of knowledge, lack of motivation to enhance entrepreneurial capacity, which further hinders the students to carry out entrepreneurial activities. From recent postgraduate practitioners situation, postgraduate selects enterprises and institutions of stable jobs when a larger proportion of employment supply. The proportion is less engaged in innovation and entrepreneurship activities.

\section{The theoretical aspects of innovation and entrepreneurship education system and framework for postgraduate are incomplete}

Currently the existing management system for postgraduate education is still not completely got rid of the planned economy, training, employment patterns. Most trained postgraduate lack the solid basics, idealistic scientific research tends, and strong practical ability. The level of technology and practical ability of postgraduate is evident. Graduate of entrepreneurial innovation will not happen overnight and must achieve from the roots through the joint efforts of all sectors of the community.

The university's traditional postgraduate education model only the focus on academic and vocational education, professional education, ignoring the student entrepreneurship education. The goal of postgraduate training is also limited to the academic and professional talents, yet the entrepreneurial talent is cultivated into postgraduate training among the target system. Most colleges and universities not only carry out entrepreneurship education during the postgraduate, but also simply create some innovation and entrepreneurship theory course. The postgraduates have some basic knowledge of entrepreneurship theory reserves on the line, and have some opportunity to practice in small businesses for innovation and entrepreneurship coupled with the self-learning ability. Theoretical system of colleges and universities on entrepreneurial talent building is not perfect, hindering the conduct of entrepreneurship education.

\section{Awareness and emphasis on innovation and entrepreneurship education in colleges and universities is not enough}

It is clear that the school managers have little or no vision regarding career guidance. The vast majority of colleges and universities did not put the current culture of innovation and entrepreneurship education as part of the mainstream education system at which teaching management has not paid sufficient attention. Innovation and entrepreneurship education act as an 
important part of university education. The importance of discipline does not doubt. Whether the innovation and entrepreneurship education is included in the technical and economic disciplines or included in corporative management disciplines is vaguely defined. The marginalized disciplinary status does not make many colleges targeting postgraduates' innovative entrepreneurship education clear enough. The utilitarian value of entrepreneurship education for postgraduates tends to be more common. Many college educators simply put innovation and entrepreneurship education as a "boss of students" education. All the innovation and entrepreneurship education is to guide and educate students to set up and founded "student enterprise". Some colleges do not have a good grasp of the relationship between professional education and entrepreneurship education, and simply conduct and professional education innovation and entrepreneurship education peel off, resulting in entrepreneurship education and professional education and learning the basics of line. It seems certain entrepreneurial kinds of skills or skills to master it.

\section{Instructor engaged in entrepreneurship education without entrepreneurial experience can not resonates with postgraduates}

In recent years, with the continuous innovation and entrepreneurship education in depth, some colleges and universities also attach great importance to guide the postgraduate entrepreneurship education. In addition to the creation of entrepreneurship education programs, the establishment of the Communist Youth League was led by the "Students' Innovative Entrepreneurship Education Guidance Center". The instructors in the center are mostly performed by the Youth League of teacher. These teachers have common basic features: a wealth of theoretical knowledge innovation and entrepreneurship, the lack of practical experience and the necessary entrepreneurship training. They do not discuss and exchange with postgraduates about theoretical operational level. It is difficult to let students have a "pioneering resonance".

Postgraduate initial are lack of funds, understanding of entrepreneurial incentives, and innovation and entrepreneurship awareness

Although local governments provide entrepreneurial incentives for postgraduates, $85 \%$ of postgraduates are not well aware of these preferential policies according to the survey data. It is unclear for them how to use incentives. Due to different entrepreneurship policy business support measures and inconsistent social security policies, a fair competitive environment is not formed. At the same time, the market complex administrative approval procedures increase the cost of human, financial, material and inhibit entrepreneurial consciousness of many postgraduates.

\section{Suggestions and Reflections on postgraduate education and training in innovation and entrepreneurship awareness}

The scientific concept of innovation and entrepreneurship education, is established and the system of education Graduate Entrepreneurship Training is improved

The real key to the implementation of innovative entrepreneurship education does not lie in the innovation and entrepreneurial potential of postgraduates, but in a college education creative itself. The teachers, university researchers and managers creative thought provide the necessary temporal and spiritual condition for the ability of postgraduates innovation and entrepreneurship education programs.

First, postgraduate training colleges should change with the times and continue to carry out reform, establish a scientific concept of innovation and entrepreneurship education, raise awareness of entrepreneurship education for postgraduates, and always put postgraduate entrepreneurship education as an important part of the reform of personnel training. The research university is not only laid in the dissemination of knowledge, but also the creation of knowledge. The creation of knowledge requires more conducive academic atmosphere for the postgraduates to develop their interests and hobbies. 
Secondly, the university should deepen the reform of postgraduate education, cultivating innovative talents to be incorporated into postgraduate training target system. The university should reflect the meaning of entrepreneurship education in the curriculum, faculty, allocation of resources and scientific research.

Third, colleges and universities should carry out entrepreneurship through education, train postgraduate entrepreneurial literacy, increase their competitiveness and entrepreneurship by means of building a sound training system and becoming innovative, managerial and entrepreneurial talents complex training base.

\section{A good atmosphere entrepreneurship education is constructed to train postgraduate innovation and entrepreneurship awareness}

The lack of clear vision among mangers is the results of lack of consensus about what constitutes effective career guidance in an educational context. It is a very difficult and complex system engineering how to create the environment for innovation and entrepreneurship postgraduate, build entrepreneurship education support, form a good business atmosphere, and stimulate innovation and entrepreneurship postgraduate impulse. Entrepreneurship education needs universities and postgraduate individual efforts to create a social atmosphere.

First, the primary responsibility for the development of society make government policies conducive to entrepreneurship postgraduate, coordinate government agencies, industry associations, business and the media to provide a reliable basis for public and institutional guarantee for postgraduate work. On the other hand the society should support and recognize postgraduate entrepreneurship education and the formation of the correct value.

Secondly, the primary responsibility for universities is changing concepts and focusing on cultivating entrepreneurial postgraduate ideologically in accordance with the requirements to develop training programs and curriculum development, to safeguard cultivating innovative talents. The universities try innovation and entrepreneurship education into teaching and training of personnel during the whole process, and make entrepreneurship education courses into credit management, encourage actively participate in entrepreneurship education and entrepreneurial practices in postgraduate school. Graduate School conduct organizational design competition, establish innovation and venture capital funds, build a good business atmosphere inside the campus.

Third, postgraduates should make full use of their initiative, actively involve in entrepreneurship education and to participate in various school activities. They could their combine expertise and entrepreneurial skills to achieve "first class" and "second class" organic combination so as to nurture their entrepreneurial thinking and entrepreneurial awareness, enhance entrepreneurship.

\section{The central role of business mentor is made}

The teachers should provide postgraduates with reliable information about their talents and with information about the knowledge and skills that needed to carry out particular jobs.It is an important guarantee for the success of education to own high quality, strong entrepreneurial university teachers. In the process of innovation and entrepreneurship training postgraduates, we can establish postgraduate business mentor system to play an exemplary role in guiding entrepreneurs and mentors in high-level innovative talents cultivation of postgraduates. In the teacher training process, we could strengthen innovation and entrepreneurship education school teacher training, to have a certain entrepreneurial coaching skills. On the other hand, there is a part in the school to hire entrepreneurial experience or experience of professional managers or company responsible guidance postgraduate entrepreneurs to help solve various problems encountered during postgraduate entrepreneurship, to provide a full range of consulting and support. Entrepreneurship education for postgraduate schools not only implement both the theoretical guidance of professional teachers, but also implement the actual operating experience of the instructor's "double mentor" guidance mode in order to better stimulate the entrepreneurial enthusiasm and innovation graduate, thereby enhancing the ability to explore graduate business practices. 


\section{A practice base established, enterprise integration focused, entrepreneurial practice experience enhanced}

Postgraduate practice base is established to explore innovation and entrepreneurship to promote academic entrepreneurship, promote entrepreneurship in academic postgraduate training new model. It is focused on creating a good business environment and atmosphere, reflecting establish training philosophy, management and operation mechanism of creative talents. It is conducive to change the "highly educated low-ability" phenomenon, and train postgraduate students into academic research and market competition reception. Universities and enterprises "marriage" is undoubtedly the production, learning and research with the model. First, the establishment of colleges, enterprises and laboratories or innovation base is considered. This will not only provide a good base for the experimental conditions for postgraduates and research practices, but also through the base for postgraduates to learn cutting-edge research in the field of application technology for the enterprise. Second, postgraduates can take advantage of entrepreneurial intention partnerships between schools and businesses to finance the creation of new businesses. On the one hand there is a mature bu siness model and management operations as venture capital protection. It has a more mature new technology. The cooperation can be achieved by schools, businesses through postgraduate of the "win-win" business model, thereby enhancing postgraduate business practices experience, achieving the purpose of developing entrepreneurial skills. Third, a number of local conditions postgraduate business incubators are constructed to give policy support. Postgraduate of the base business enterprises provide training and guidance services, the implementation of policies to support efforts to improve the success rate of entrepreneurship and prolong survival of the enterprise.

\section{Summary}

Innovation and entrepreneurship education summon a new era. To recognize the special nature of such education, universities should train postgraduates through cultural, entrepreneurial role models, case studies entrepreneurship and entrepreneurial internship training and other means. In addition, colleges and universities carry out a systematic way to re-quality, highlighting the effective organization and integration, innovation and entrepreneurship education. The entrepreneurship education and innovation-related services, security and incentives, such as teacher education reform fund innovation and entrepreneurship, technological innovation or entrepreneurship practice student scholarships, are developed.

\section{Acknowledgement}

This research was financially supported by The Ministry of Education of Humanities and Social Science Project (No.09YJC710008), Jiangxi Degree and Postgraduate Education Teaching Reform Research Subject (No. JXYJG-2011-028, JXYJG-2012-057), Jiangxi Province Social Science The 12th Five-year Plan (No.12IY14).

\section{References}

[1] G. T. Solomon, Trends in small business management and entrepreneurship education in the United States, Entrep. Theory. Pract., 15(1991) 25-40.

[2] L. W. Busenitz, G. P. West, Entrepreneurship Research in Emergence: Past Trends and Future Directions, J. Manage., 29(2003) 295-305. 